\title{
EXPLORING STUDENT TEACHERS' LEARNING STRATEGIES AND THE RELATIONSHIP WITH ACADEMIC ACHIEVEMENT AND DEMOGRAPHIC VARIABLES
}

\author{
Esther Chiner ${ }^{1}$, Marcos Gómez-Puerta ${ }^{2}$, \& María Cristina Cardona-Moltó ${ }^{1}$ \\ ${ }^{1}$ Department of Health Psychology, University of Alicante (Spain) \\ ${ }^{2}$ Department of Developmental Psychology and Teaching, University of Alicante (Spain)
}

\begin{abstract}
Diversity in Higher Education implies being able as teachers to meet students' needs and preferences to motivate them and facilitate their development and learning. This diversity derives, among others, from students' learning styles and strategies which can determine their academic success or failure. The purpose of this study was to examine student teachers' learning strategies and to determine whether these strategies differ according to some demographic variables (i.e. gender, Bachelor's degree, year of study) and students' academic performance. To this end, a cross-sectional survey design was conducted, and a convenience sample of 141 student teachers (20 males and 121 females) participated in the study. Students were enrolled in the first and second year of two Bachelor's degrees in Education: Early Education $(n=75)$ and Elementary Education $(n=66)$. Participants' age ranged between 18 and 42 years old $(M=19.88, S D=2.73)$. The 5-point Likert scale questionnaire CEVEAPEU (Gargallo, Suárez-Rodríguez, \& Pérez-Pérez, 2009) was administered during class time and descriptive and inferential analyses were conducted. Overall, student teachers report high intrinsic motivation, task value and internal attributions, as well as high levels of self-efficacy and expectations. Concerning strategies related to information processing, students highlighted the elaboration, transfer and use of information. Female students showed greater intrinsic motivation and anxiety control than males and used more strategies related to information elaboration, organization and transfer. Early education student teachers scored higher than elementary education student teachers in motivational, affective and information search and selection strategies. Second-year students showed greater motivational strategies than first-year students. They also scored higher in metacognitive strategies such as planning and in information processing and use strategies. Unexpectedly, students with lower academic performance, reported greater use of planning strategies and other strategies related to information processing, compared to those with average academic achievement. Differences in students' learning strategies highlight the need for accommodating the teaching styles to the characteristics of university students and also the development of programs oriented towards the improvement of students' strategic learning.
\end{abstract}

Keywords: Learning strategies, academic achievement, gender, student teachers, higher education.

\section{Introduction}

Research in learning strategies has aroused a growing interest in Higher Education since it is considered to be an important factor in university students' development and academic success (Amir, Jelas, \& Rahman, 2011; Bahamón, Vianchá, Alarcón, \& Bohórquez, 2013). Students not only differ in their interests, expectations, previous experiences or abilities, but also in the way they learn, and these differences in their strategic learning may have an impact on their academic achievement (Mohammadi, Thaghinejad, Suhrabi, \& Tavan, 2017; Renzulli, 2015).

Learning strategies are a multidimensional construct that has been conceptualized differently depending on the theoretical framework and the subsequent instrument used to evaluate them. This lack of consensus has generated confusion and has hindered understanding and generalization in the educational context (Valadez Huizar, 2009). However, there is agreement that, from a constructivist perspective of learning in which a series of cognitive processes and mental operations are carried out to acquire, encode and retrieve information (Ausubel, Novak, \& Hanesian, 1998; Bandura, 1987; Flavell, 1996; Gagné, 1970), students need to use skills and processes that also analyze, transform and apply that information to succeed in learning. Overall, the construct of learning strategies includes not only cognitive (i.e. information processing organization and management) and metacognitive elements (i.e. self-regulation in the learning process) but also socio-affective and motivational components (i.e. disposition for learning). Therefore, the learning strategies can be understood as an organized, 
conscious and intentional set of skills and actions that the learner carries out to effectively achieve a learning goal in a given social context (Gargallo et al., 2009).

Research has shown that the use of different learning strategies is associated to students' academic performance and other background characteristics (e.g. Camarero, Martín del Buey, \& Herrero Díez, 2000; Juárez, Rodríguez Hernández, Escoto, \& Luna, 2016). Overall, university students use strategies related to codification, learning support and learning skills (Bahamón et al., 2013; Rossi Casé, Neer, Doná, \& Lopetegui, 2010). However, differences in students' use of learning strategies can be found. For instance, Gargallo (2006) and Juárez et al. (2016) concluded that students with higher academic performance use more learning strategies, especially those related to information search, selection and processing, and metacognitive and context control strategies. Likewise, research has shown that students enrolled in different degree programs seem to use different learning strategies (Camarero et al., 2000; Gargallo, 2006) and they use more effective strategies throughout the years of study (Camarero et al., 2000; Gargallo, Almerich, Suárez-Rodríguez, \& García-Félix, 2012). Other studies have found differences in the strategic learning of male and female students (Ghiasvand, 2010; Rossi Casé et al., 2010). These findings suggest that university students differ in the way they learn and may result in different levels of academic success.

Further research is needed to establish the factors that may affect students' academic performance and, among these factors, the learning strategies seem to be crucial. By determining the way students learn and their characteristics, we will be able to accommodate the teaching styles and practices, and carry out interventions oriented to improve students' strategic learning and, subsequently, their academic performance.

\section{Objectives}

The purpose of this study was to identify student teachers' use of learning strategies. It also aimed to determine the relationship between these strategies and students' academic performance, gender, degree program and year of study.

\section{Methods}

\subsection{Participants}

A convenience sample of 141 students enrolled in two undergraduate degree programs in Education of a Spanish university participated in the study. The majority were female students $(n=121$, $86 \%$ ) with an average age of 19.88 years old $(S D=2.73)$. In terms of degree programs, 75 students were enrolled in Early Childhood Education (53\%) and 66 in Primary School Education (47\%). Concerning the year of study, 97 students were in their first year (69\%) and 44 in their second year (31\%).

\subsection{Instruments}

The CEVEAPEU questionnaire developed by Gargallo et al. (2009) was used for this study. The instrument measures the learning strategies used by university students and comprises 25 strategies organized in two scales and six subscales. Participants had to respond to 88 items in a 5-point-Likert scale $(1=$ totally disagree, 5 = totally agree $)$. The questionnaire showed good internal consistency for the total scale $(\alpha=.97)$ and for each the scales: Affective, support and control strategies $(\alpha=.95)$ and Information processing strategies $(\alpha=.94)$. The alpha values for the six subscales ranged between .67 and .94 .

Demographic information (i.e. gender, age, degree program, year of study) was also included in the questionnaire. To collect information about the academic performance, first-year students were asked to provide the grade obtained in the University Access Exam. Second-year students had to provide the grades obtained in six compulsory subjects studied the year before.

\subsection{Procedure}

A descriptive and comparative study was carried out based on a survey design. The study guaranteed the ethical standards in research through the anonymization of the questionnaires and the request for the informed consent of all participants. Students were asked to complete the online version of the questionnaire during class time and the time required to complete it was 15-20 minutes.

\subsection{Data analyses}

Descriptive analyses were performed to identify the use of learning strategies by student teachers. Differences between students' level of academic achievement were analysed using a one-way ANOVA. To compare the use of learning strategies concerning the gender, degree program and year of study a series of independent samples t-test were used. 


\section{Results}

\subsection{Student teachers' use of learning strategies}

Overall, student teachers use both affective, support and control strategies $(M=3.55, S D=0.55)$ and information processing related strategies $(M=3.54, S D=0.69)$ moderately. Participants rated high motivational strategies such as intrinsic motivation $(M=4.06, S D=0.82)$, task value $(M=4.25$, $S D=0.81)$, task persistence $(M=3.98, S D=0.82)$ and self-efficacy and expectations $(M=3.92$, $S D=0.79)$ as well as strategies related to processing and use of information like elaboration $(M=3.16$, $S D=0.92)$ and information transfer $(M=3.91, S D=0.86)$. Other strategies such as extrinsic motivation $(M=2.24, S D=0.99)$, attributions $(M=2.67, S D=0.86)$ and simple repetition $(M=2.97, S D=1.06)$ were poorly rated.

\subsection{Comparing learning strategies and academic performance}

Significant differences were found concerning the use of learning strategies by student teachers and their academic performance. The group of students with low academic performance stated that they used the metacognitive strategy of planning $(M=3.03, S D=0.69)$ more than the medium academic group $(M=2.58, S D=0.57)$, while the latter used this strategy less than high achievers $(M=2.90, S D=0.64$, $F(2,138)=6.148, p=.003)$.

In addition, low achievers used some information processing related strategies more often than medium and high achievers. For instance, they declared they had more knowledge of sources and information search $(M=3.34, S D=0.69)$ than medium achievers $(M=2.93, S D=0.80$, $F(2,137)=3.994, p=021)$. They also used more strategies for information acquisition (low achievers: $M=3.45, S D=.89$; medium achievers: $M=2.91, S D=0.89, F(2,137)=4.52, p=.012)$, organization (low achievers: $M=4.04, S D=.69$; medium achievers: $M=3.60, S D=1.01$, high achievers: $M=3.57$, $S D=0.93, F(2,138)=4.33, p=.015)$ and resource management (low achievers: $M=3.88, S D=.90$; high achievers: $M=3.43, S D=0.83, F(2,138)=4.52, p=.012)$.

\subsection{Comparing student teachers' learning strategies and background characteristics}

Significant differences were found concerning student teachers' gender, degree program and year of study $(p<.05)$. Details are displayed in Table 1.

Overall, female students showed more intrinsic motivation and anxiety control than male students. They also used more information processing strategies such as elaboration, organization, transfer, and resource management.

Likewise, students enrolled in the Early Childhood Education program showed greater task value, anxiety control, knowledge of sources and information search, and information acquisition than students enrolled in the Primary School Education program.

Finally, second-year students used greater motivational strategies like intrinsic motivation, task value and self-efficacy and expectations compared to first-year students. They also scored higher in the metacognitive strategy of planning and information processing strategies like organization, transfer and resource management.

Table 1. Differences in student teachers' use of learning strategies concerning background characteristics.

\begin{tabular}{|c|c|c|c|c|c|c|c|c|c|c|c|c|c|c|c|}
\hline \multirow[b]{3}{*}{ Strategy } & \multicolumn{5}{|c|}{ Gender } & \multicolumn{5}{|c|}{ Degree program } & \multicolumn{5}{|c|}{ Year of study } \\
\hline & \multicolumn{2}{|c|}{ Male } & \multicolumn{2}{|c|}{ Female } & \multirow[b]{2}{*}{$t(139)$} & \multicolumn{2}{|c|}{$\begin{array}{c}\text { Early } \\
\text { Childhood } \\
\text { Education }\end{array}$} & \multicolumn{2}{|c|}{\begin{tabular}{|c|} 
Primary \\
School \\
Education
\end{tabular}} & \multirow[b]{2}{*}{$t(139)$} & \multicolumn{2}{|c|}{ First year } & \multicolumn{2}{|c|}{$\begin{array}{l}\text { Second } \\
\text { year }\end{array}$} & \multirow[b]{2}{*}{$t(139)$} \\
\hline & $M$ & $S D$ & $M$ & $S D$ & & $M$ & $S D$ & $M$ & $S D$ & & $M$ & $S D$ & $M$ & $S D$ & \\
\hline Intrinsic motivation & 3.56 & 0.89 & 4.15 & 0.78 & $3.03 * *$ & & & & & & 3.97 & 0.90 & 4.28 & 0.55 & $2.08^{*}$ \\
\hline Task value & & & & & & 4.39 & 0.73 & 4.08 & 0.86 & $2.32 *$ & 4.12 & 0.89 & 4.53 & 0.47 & $2.87 * *$ \\
\hline Anxiety control & 2.91 & 0.79 & 3.26 & 0.68 & $2.08^{*}$ & 3.38 & 0.76 & 3.39 & 0.84 & $3.11 * *$ & & & & & \\
\hline $\begin{array}{l}\text { Self-efficacy and } \\
\text { expectation }\end{array}$ & & & & & & & & & & & 3.83 & 0.85 & 4.11 & 0.58 & $2.01 *$ \\
\hline $\begin{array}{l}\text { Knowledge of } \\
\text { sources and } \\
\text { information search }\end{array}$ & & & & & & 3.23 & 0.69 & 2.95 & 0.82 & $2.16^{*}$ & & & & & \\
\hline Planning & & & & & & & & & & & 2.77 & 0.67 & 3.02 & 0.60 & $2.11 *$ \\
\hline $\begin{array}{l}\text { Information } \\
\text { acquisition }\end{array}$ & & & & & & 3.33 & 0.85 & 2.96 & 0.97 & $2.39 *$ & & & & & \\
\hline Elaboration & 3.57 & 1.10 & 4.12 & 0.80 & $2.67^{*}$ & & & & & & & & & & \\
\hline Organization & 3.28 & 0.99 & 3.83 & 0.86 & $2.58 *$ & & & & & & 3.64 & 0.93 & 3.99 & 0.78 & $2.17^{*}$ \\
\hline Transfer & 3.48 & 0.98 & 3.99 & 0.82 & $2.47 *$ & & & & & & 3.78 & 0.92 & 4.21 & 0.63 & $2.83 * *$ \\
\hline $\begin{array}{l}\text { Resource } \\
\text { management }\end{array}$ & 3.10 & .094 & 3.71 & 0.88 & $2.86 * *$ & & & & & & 3.48 & 0.93 & 3.94 & 0.80 & $2.77 * *$ \\
\hline
\end{tabular}

Significant at $* p<.05, * * p<.01$ 


\section{Discussion and conclusions}

This study aimed to explore student teachers use of learning strategies and determine whether the use of these strategies differ depending on their academic performance and other background characteristics (i.e. gender, degree program, year of study). Findings showed some contradictory results about students' academic achievement. While previous studies report greater and more complex use of learning strategies by students with high academic performance (e.g. Bahamón et al., 2013; Juárez et al., 2016; Salazar \& Heredia, 2019), the present study barely found differences between high, medium and low achievers in line with other previous research (e.g. Martínez \& Galán, 2000; Rossi Casé et al., 2010; Trelles, Alvarado, \& Montánchez, 2018). Unexpectedly, when differences were identified, student teachers with low performance stated greater use of those strategies compared to medium achievers (i.e. planning, information acquisition, organization) and high achievers (i.e. information organization and resource management). Further research is needed to better understand the factors that underlie these findings.

Concerning student teachers' background characteristics, differences between groups were found. In line with Ghiasvand's work (2010), female students use more learning strategies than male students, specifically, intrinsic motivation, anxiety control and information processing strategies. Additionally, students from different degree programs differ in the way they use some learning strategies. Research had already highlighted this issue (Camarero et al., 2000; Gargallo, 2006) and further investigation should include other degree programs to confirm this pattern. Finally, as Gargallo (2012) and Salazar \& Heredia (2019) had already pointed out, the use of learning strategies evolves throughout the years. The present study showed greater use of learning strategies by second-year students compared to first-year students. These findings suggest that students learn more efficiently as they gain experience during their training. A longitudinal study that explores the evolution of students' use of learning strategies would help to identify the initial needs of university students and set the supports and interventions to improve their strategic learning.

This research presents several limitations. In the first place, the cross-sectional nature of this study and the size of the sample do not allow the generalization of the results to the population of student teachers. This study only reflects the perceptions of a group of students and may not coincide with those of other institutions. Secondly, participants' responses may not reflect their actual use of learning strategies since they may have indicated biased or socially desirable responses (e.g. low achievement students).

Nevertheless, and in light of these findings, we can conclude that (a) high and low achievers do not necessarily use different learning strategies, (b) female students are better strategic learners, (c) different degree programs may require different learning strategies, and (d) students become more effective in their strategic learning throughout the years of study. Differences in the way students learn highlight the need for accommodating the teaching styles to the characteristics of university students and the degree program they are enrolled in as well as the development of interventions oriented to improve students' strategic learning.

\section{References}

Amir, R., Jelas, Z. M., \& Rahman, S. (2011). Learning styles of university students: Implications for teaching and learning. World Applied Sciences Journal, 14, 22-26.

Ausubel, D. P., Novak, J. D., \& Hanesian, H. (1998). Psicología educativa: un punto de vista cognoscitivo. México: Trillas.

Bahamón, M. J., Vianchá, M. A., Alarcón, L. L., \& Bohórquez, C. I. (2013). Estilos y estrategias de aprendizaje relacionados con el logro académico en estudiantes universitarios. Pensamiento Psicológico, 11(1), 115-129.

Bandura, A. (1987). Teoría del aprendizaje social. Madrid: Espasa-Calpe.

Camarero, F., Martín del Buey, F., \& Herrero Díez, J. (2000). Estilos y estrategias de aprendizaje en estudiantes universitarios. Psicothema, 12(4), 615-622.

Flavell, J. H. (1996). El desarrollo cognitivo (2a ed.). Madrid: Visor.

Gagné, R. (1970). Las condiciones del aprendizaje. Madrid: Aguilar.

Gargallo, B. (2006). Estrategias de aprendizaje rendimiento y otras variables relevantes en estudiantes universitarios. Revista de Psicología General y Aplicada, 59(1-2), 109-130.

Gargallo, B., Almerich, G., Suárez-Rodríguez, J. M., \& García-Félix, E. (2012). Estrategias de aprendizaje en estudiantes universitarios excelentes y medios. Su evolución a lo largo del primer año de carrera. RELIEVE: Revista Electrónica de Investigación y Evaluación Educativa, 18(2), art. 1. doi:10.7203/relieve.18.2.2001 
Gargallo, B., Suárez-Rodríguez, J. M., \& Pérez-Pérez, C. (2009). El cuestionario CEVEAPEU. Un instrumento para la evaluación de las estrategias de aprendizaje de los estudiantes universitarios. Revista Electrónica de Investigación y Evaluación Educativa, 15(2), 1-31.

Ghiasvand, M. Y. (2010). Relationship between learning strategies and academic achievement; based on information processing approach. Procedia - Social and Behavioral Sciences, 5, 1033-1036. doi:10.1016/j.sbspro.2010.07.231

Juárez, C. S., Rodríguez Hernández, G., Escoto, M. C., \& Luna, E. (2016). Relación de los estilos y estrategias de aprendizaje con el rendimiento académico en estudiantes universitarios. Journal of Learning Styles, 9(17), 268-288.

Martínez, J. R., \& Galán, F. (2000). Estrategias de aprendizaje, motivación y rendimiento académico en alumnos universitarios. Revista Española De Orientación Y Psicopedagogía, 11(19), 35-50.

Mohammadi, I., Thaghinejad, H., Suhrabi, Z., \& Tavan, H. (2017). The correlation of learning and study strategies with academic achievement of nursing students. Journal of Basic Research in Medical Sciences, 4(3), 8-13. https://doi.org/10.29252/jbrms.4.3.8

Renzulli, S. J. (2015). Using Learning Strategies to Improve the Academic Performance of University Students on Academic Probation. NACADA Journal, 35(1), 29-41. https://doi.org/10.12930/NACADA-13-043

Rossi Casé, L. E., Neer, R. H., Doná, S., \& Lopetegui, M. S. (2010). Estrategias de aprendizaje y rendimiento académico según el género en estudiantes universitarios. SRevista de psicología, 11, 199-211. Retrieved from http://www.memoria.fahce.unlp.edu.ar/art revistas/pr.4846/pr.4846.pdf

Salazar, I., \& Heredia, Y. (2019). Estrategias de aprendizaje y desempeño académico en estudiantes de Medicina. Educación Médica, 20(4), 256-262. https://doi.org/10.1016/j.edumed.2018.12.005

Trelles, H. J., Alvarado, H. P., \& Montánchez, M. L. (2018). Estrategias y estilos de aprendizaje y su relación con el rendimiento académico en estudiantes universitarios de Psicología Educativa. Revista Killkana Sociales, 2(2), 9-16. https://doi.org/10.26871/killkana_social.v2i2.292

Valadez Huizar, M. (2009). Estilos de aprendizaje y estilos de pensamiento: precisiones conceptuales. Revista de Educación y Desarrollo, 11, 19-30. 